\title{
TENTOONSTELLING: PRONKSTUKKEN UIT KEIZERLIJK JAPAN, MEIJI-KUNST UIT DE KHALILI COLLECTIE
}

De Japanse stand op de Centennial Exhibition in Philadelphia 1876 was volgens een van de bezoekers 'een van de grote verrassingen van de tentoonstelling. We troffen er een overvloed aan bewijzen dat het [Japan] de meeste ontwikkelde naties van Europa in de kunsten overtreft." ${ }^{\text {" Dat de }}$ Japanse inzending naar de wereldtentoonstelling in Chicago in 1893 zo mogelijk een nog groter succes was, blijkt wel uit het volgende commentaar: 'In het niet al te verre verschiet, wanneer we inzendingen ontvangen naar onze internationale tentoonstellingen van de bewoners van Mars, zullen deze stukken vermoedelijk niet meer verschillen van die van onszelf dan de stukken van het Keizerrijk Japan op de huidige tentoonstelling in Chicago. De Europeaan of Amerikaan die deze zalen binnenkomt, herkent meteen een nieuwe orde der dingen en een nieuwe wereld, alsof ze afkomstig zijn van ergens voorbij de sterren.'

Uit de befaamde Khalili collectie, 's werelds grootste en meest veelzijdige privé-verzameling op het gebied van Meiji-kunst, brengt het Van Gogh Museum een selectie van ruim 200 objecten bijeen onder de titel 'Pronkstukken uit keizerlijk Japan. Meiji-kunst uit de Khalili collectie'. De werken werden gemaakt in de periode van de 'verlichte regering' van keizer Meiji (1868-1912). Nooit eerder werd op het Europese vasteland een uitgebreide tentoonstelling gewijd aan de Meiji-kunst uit deze collectie.

Tijdens de regeringsperiode van keizer Meiji vond een opmerkelijke ontwikkeling plaats in de Japanse kunst. Deze werd mede ingegeven door het wegvallen van de traditionele markt als gevolg van de grote sociale veranderingen in het sinds 1854 opengestelde Japan. Tegelijkertijd werd de buitenlandse markt ontdekt. De Meiji-kunst bouwde voort op traditionele vormen, decoraties en technieken, waarbij perfectie en raffinement centraal stonden. De opmerkelijk synthese van conventie en innovatie leidde tot een totaal vernieuwde porselein- en email cloisonné-productie. Ook in lakwerk en metaalbewerking was een ongekende ontwikkeling zichtbaar. Op de wereldtentoonstellingen in Europa en Amerika verraste Japan het Westen met zijn vazen, lakdozen, panelen en zelfs hele kasten.

\footnotetext{
Afbeelding 1

Anoniem kunstenaar, de firma Ozeki, bonbonnière, okashibako, Shôki de demonenbedwinger die op drie demonen jaagt, circa 1885 , zilver, goud, shakudô en email cloisonne gevat in gouddraad, 44 cm, Mo58
}

'Pronkstukken uit keizerlijk Japan' bevat hiervan vele voorbeelden en een vier meter hoge bronzen wierookbrander met een adelaar vormt het absolute pronkstuk. Meesters zoals Miyagawa Kôzan (porselein), Yabu Meizan (aardewerk), Namikawa Sôsuke (email cloisonné), Shibata Zeshin (lakwerk) en Suzuki Chôkichi (brons) tonen hun kunnen in kunstwerken die blijk geven van een zo goed als volmaakte technische en artistieke perfectie en wel beschouwd worden als het toppunt van de decoratieve Meiji-stijl. 


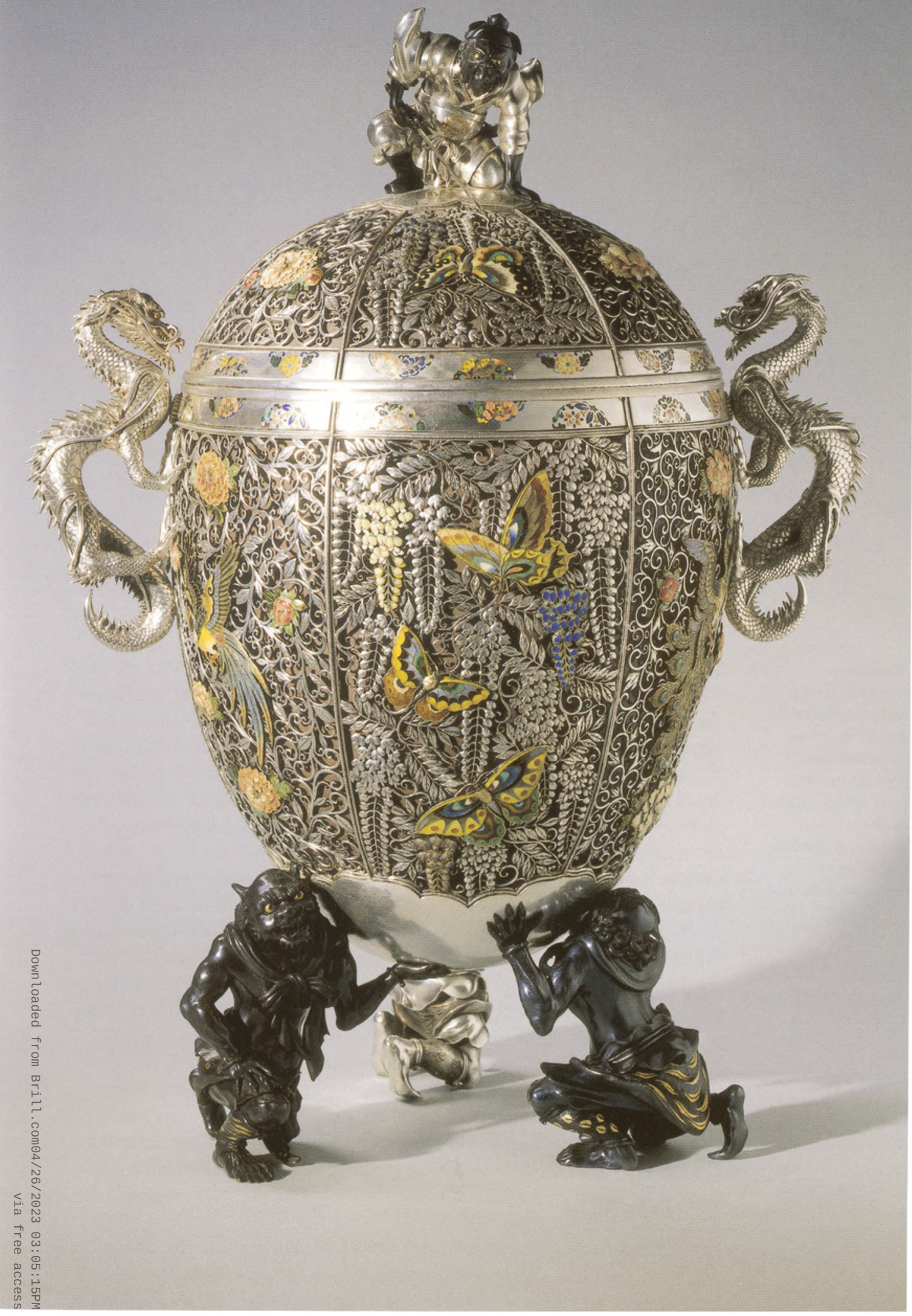



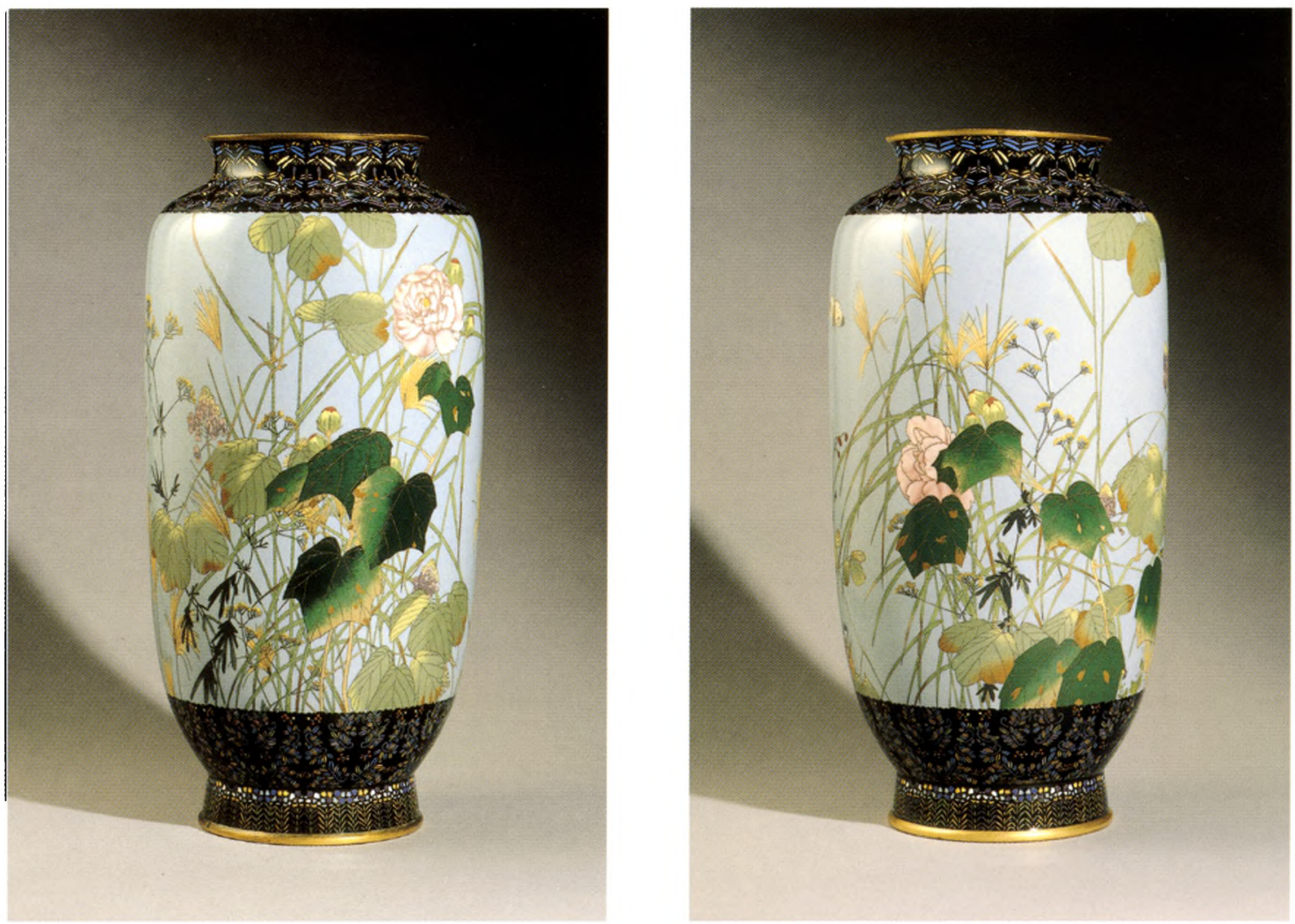

Afbeelding 2 Namikawa Sósuke atelier (toegeschreven), een stel vazen met herfstbloemen en vlinders, circa 1883 , émail cloisonné in goud en zilverdraad op metaal, met vergulde randen aan hals en voet, 55,2 cm, Eorgl/R
Twee voorbeelden kunnen deze artistieke perfectie illustreren. Een eivormige schaal met deksel wordt bedekt met opengewerkte wisteria in zilver, hier en daar opgefleurd door feniksen en vlinders in email cloisonné in gouddraad (afb. 1). Deze presenteerdoos voor lekkernijen, okashibako doet denken aan de zeer prijzige Russische Fabergé eieren waaraan met hetzelfde gevoel voor detail is gewerkt. Hoewel waarschijnlijk nooit als bonbonnière gebruikt, wordt dit in principe praktische voorwerp tot een waarachtig kunstwerk door zijn decoratieve attributen. Demonenjager Shôki zit bovenop het deksel, zijn tweezijdig geslepen zwaard in de hand. Zijn gezicht, armen en benen zijn van het donkere shakudô, een koperlegering met een kleine hoeveelheid goud, en zijn kleding is van zilver. Deze Shôki kwam voort uit een nachtmerrie van de Chinese keizer Tang Xuanzong (r. 712-756; Japans: Meikô). Gelukkig was zijn hofschilder Wu Daozi in staat deze overtuigde duiveljager te schilderen, een beeltenis die vooral in Japan buitengewoon populair werd. Maar anders dan Zhong Kui in China werd 'Shôki' in Japan vooral onderwerp van humoristische voorstellingen. Op deze bonbonnière heeft hij nog wel zijn Chinese uiterlijk en kleding mogen behouden, zoals een hoed met twee zijflappen. Hij kijkt hier om zich heen, zoekend naar de drie duiveltjes die zich onder de bonbonnière verstopt hebben en zo tevens als ondersteuning dienen, één in zilver, de twee andere in shakudô. Op hun beurt kijken de demonen angstig omhoog.

Een stel hoge vazen gedecoreerd met herfstbloemen als hibiscus, pampa gras, ominaeshi (Patrinia scabiosifolia), en dartelende vlinders tegenoeen licht -03 : 05:15PM blauwe lucht zijn toegeschreven aan Namikawa Sôsuke (afb. 2). Ze'latenéeencess 
schitterend contrast zien tussen de strakke zwarte mozaïekbanden met een zwerm libellen rond de nek en een strakker herhaald bloemmotief op de voet en het schilderachtige middenpaneel met in de bladeren van licht- naar donkergroen verlopende kleuren. Naar eigen zeggen vond Sôsuke het procedé van verlopende kleuren in maart 1879 uit. Hij en de firma Nagoya Cloisonné kregen voor deze vazen een gouden medaille van de $1^{\mathrm{e}}$ klasse op de 'Internationale Koloniale en Uitvoerhandel Tentoonstelling' die in 1883 werd gehouden op het terrein achter het in aanbouw zijnde Rijksmuseum, het huidige Museumplein. Deze onderscheiding werd uitgereikt door Koning Willem III.

Vincent van Gogh had een grote bewondering voor Japanse kunst en begon in Parijs met het aanleggen van een collectie Japanse prenten, die thans in het Van Gogh Museum wordt bewaard. Hij werd er gelukkig en vrolijk van, zo schreef hij en in brieven aan zijn broer Theo komt zijn waardering voor Japanse kunst meerdere keren ter sprake. In de tentoonstelling Pronkstukken uit keizerlijk Japan. Meiji-kunst uit de Khalili collectie zijn ook schilderijen van Van Gogh, Japanse albums en prenten te bewonderen. Aan de hand van deze werken wordt getoond hoe Van Gogh typisch Japanse thema's zoals bloesems en irissen verwerkte in zijn schilderijen. Daarnaast zijn enkele voorbeelden van vrije kopieën van Van Gogh naar Japanse houtsneden zien.

- De 'Japanse Zomer' in het Van Gogh Museum vindt plaats in het tentoonstellingsgebouw van 7 juli - 22 oktober 2006

'Pronkstukken uit keizerlijk Japan' is één van de drie tentoonstellingen die er te bezichtigen zijn.

- Ook te zien:

'Vrouwen van Tokio \& Parijs' samengesteld door gastconservatoren Kris Schiermeier en Matthi Forrer (conservator Japanse kunst, Rijksmuseum voor Volkenkunde te Leiden)

'De Tokaido Gaandeweg' een hedendaagse visie op de 53 stations van de 'Tokaidô' van de Nederlandse fotograaf Guus Rijven

\section{Lees-suggesties}

Joe Earle, Splendors of Imperial Japan. Arts of the Meiji Period from the Khalili Collection (tent.cat.), Londen, 2002.

Oliver Impey, Malcolm Fairley, Joe Earle (red.), The Nasser D. Khalili Collection of Japanese Art. Meiji no Takara, Treasures of Imperial Japan (negen delen), Londen, 1995.

Kris Schiermeier, Matthi Forrer, Pronkstukken uit keizerlijk Japan, Meiji-kunst uit de Khalili collectie, Amsterdam, 2006.

\section{Noten}

1. Geciteerd in Neil Harris, 'All the World a melting Pot? Japan at American Fairs, 1876-1904', in: Akira Iriye (red.), Mutual Images: Essays in American-Japanese Relations, Cambridge, Massachusetts 1975, p. 29.

2. Geciteerd in William Hosley, The Japan Idea: Art and Life in Victorian America, Hartford, Connecticut 1990, p. 14. 